NASA/CR-2003-211822

Acceptable Tolerances for Matching Icing Similarity Parameters in Scaling Applications

David N. Anderson

Ohio Aerospace Institute, Brook Park, Ohio 
Since its founding, NASA has been dedicated to the advancement of aeronautics and space science. The NASA Scientific and Technical Information (STI) Program Office plays a key part in helping NASA maintain this important role.

The NASA STI Program Office is operated by Langley Research Center, the Lead Center for NASA's scientific and technical information. The NASA STI Program Office provides access to the NASA STI Database, the largest collection of aeronautical and space science STI in the world. The Program Office is also NASA's institutional mechanism for disseminating the results of its research and development activities. These results are published by NASA in the NASA STI Report Series, which includes the following report types:

- $\quad$ TECHNICAL PUBLICATION. Reports of completed research or a major significant phase of research that present the results of NASA programs and include extensive data or theoretical analysis. Includes compilations of significant scientific and technical data and information deemed to be of continuing reference value. NASA's counterpart of peerreviewed formal professional papers but has less stringent limitations on manuscript length and extent of graphic presentations.

- TECHNICAL MEMORANDUM. Scientific and technical findings that are preliminary or of specialized interest, e.g., quick release reports, working papers, and bibliographies that contain minimal annotation. Does not contain extensive analysis.

- CONTRACTOR REPORT. Scientific and technical findings by NASA-sponsored contractors and grantees.
- CONFERENCE PUBLICATION. Collected papers from scientific and technical conferences, symposia, seminars, or other meetings sponsored or cosponsored by NASA.

- SPECIAL PUBLICATION. Scientific, technical, or historical information from NASA programs, projects, and missions, often concerned with subjects having substantial public interest.

- TECHNICAL TRANSLATION. Englishlanguage translations of foreign scientific and technical material pertinent to NASA's mission.

Specialized services that complement the STI Program Office's diverse offerings include creating custom thesauri, building customized data bases, organizing and publishing research results ... even providing videos.

For more information about the NASA STI Program Office, see the following:

- Access the NASA STI Program Home Page at http://www.sti.nasa.gov

- E-mail your question via the Internet to help@sti.nasa.gov

- Fax your question to the NASA Access Help Desk at 301-621-0134

- Telephone the NASA Access Help Desk at 301-621-0390

- Write to:

NASA Access Help Desk

NASA Center for AeroSpace Information 7121 Standard Drive

Hanover, MD 21076 
NASA/CR-2003-211822

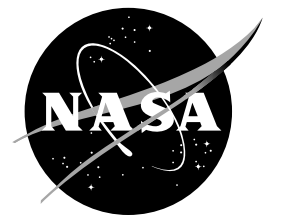

\section{Acceptable Tolerances for Matching Icing Similarity Parameters in Scaling Applications}

David N. Anderson

Ohio Aerospace Institute, Brook Park, Ohio

Prepared for the

39th Aerospace Sciences Meeting and Exhibit

sponsored by the American Institute of Aeronautics and Astronautics

Reno, Nevada, January 8-11, 2001

Prepared under Cooperative Agreement NCC3-884

National Aeronautics and

Space Administration

Glenn Research Center 


\section{Acknowledgments}

The NASA Glenn Research Center Icing Branch supported this work under a grant to the Ohio Aerospace Institute. The author is also grateful to Gary Ruff for helpful discussions and suggestions.

This report contains preliminary

findings, subject to revision as analysis proceeds.

The Aerospace Propulsion and Power Program at NASA Glenn Research Center sponsored this work.

Available from

NASA Center for Aerospace Information 7121 Standard Drive

Hanover, MD 21076
National Technical Information Service 5285 Port Royal Road Springfield, VA 22100 


\title{
ACCEPTABLE TOLERANCES FOR MATCHING ICING SIMILARITY PARAMETERS IN SCALING APPLICATIONS
}

\author{
David N. Anderson* \\ Ohio Aerospace Institute \\ Brook Park, Ohio 44142
}

\begin{abstract}
$\underline{\text { Abstract }}$
This paper reviews past work and presents new data to evaluate how changes in similarity parameters affect ice shapes and how closely scale values of the parameters should match reference values. Experimental ice shapes presented are from tests by various researchers in the NASA Glenn Icing Research Tunnel. The parameters reviewed are the modified inertia parameter (which determines the stagnation collection efficiency), accumulation parameter, freezing fraction, Reynolds number and Weber number.

It was demonstrated that a good match of scale and reference ice shapes could sometimes be achieved even when values of the modified inertia parameter did not match precisely. Consequently, there can be some flexibility in setting scale droplet size, which is the test condition determined from the modified inertia parameter. A recommended guideline is that the modified inertia parameter be chosen so that the scale stagnation collection efficiency is within $10 \%$ of the reference value. The scale accumulation parameter and freezing fraction should also be within $10 \%$ of their reference values. The Weber number based on droplet size and water properties appears to be a more important scaling parameter than one based on model size and air properties. Scale values of both the Reynolds and Weber numbers need to be in the range of 60 to $160 \%$ of the corresponding reference values. The effects of variations in other similarity parameters have yet to be established.
\end{abstract}

\section{Nomenclature}

$\begin{array}{ll}A_{c} & \text { Accumulation parameter, dimensionless } \\ b & \text { Relative heat factor, dimensionless } \\ c & \text { Airfoil chord, } \mathrm{cm} \\ c_{p, w s} & \begin{array}{l}\text { Specific heat of water at the surface } \\ \text { temperature, cal } / \mathrm{g} \mathrm{K}\end{array} \\ d & \begin{array}{l}\text { Cylinder diameter or twice the leading-edge } \\ \text { radius of airfoil, } \mathrm{cm}\end{array}\end{array}$

*Senior Research Associate, Member AIAA $h_{c} \quad$ Convective heat-transfer coefficient, $\mathrm{cal} / \mathrm{s} \mathrm{m}^{2} \mathrm{~K}$

$h_{G} \quad$ Gas-phase mass-transfer coefficient, $\mathrm{g} / \mathrm{s} \mathrm{m}^{2}$

$K \quad$ Inertia parameter, dimensionless

$K_{0} \quad$ Modified inertia parameter, dimensionless

$L W C \quad$ Cloud liquid-water content, $\mathrm{g} / \mathrm{m}^{3}$

$M \quad$ Mach number, dimensionless

MVD Water droplet median volume diameter, $\mu \mathrm{m}$

$n \quad$ Freezing fraction, dimensionless

$p_{s t} \quad$ Static pressure, $\mathrm{Nt} / \mathrm{m}^{2}$

$r \quad$ Recovery factor, dimensionless

Re Reynolds number of model, dimensionless

$R_{\delta} \quad$ Reynolds number of water droplet, dimensionless

$s \quad$ Distance from stagnation line, $\mathrm{cm}$

$t_{f} \quad$ Freezing temperature, ${ }^{\circ} \mathrm{C}$

$t_{s} \quad$ Surface temperature, ${ }^{\circ} \mathrm{C}$

$t_{s t} \quad$ Static temperature, ${ }^{\circ} \mathrm{C}$

$t_{\text {tot }} \quad$ Total temperature, ${ }^{\circ} \mathrm{C}$

$V \quad$ Air velocity, $\mathrm{m} / \mathrm{s}$

We Weber number based on droplet size and water properties, dimensionless

$W e_{c} \quad$ Weber number based on model size and air properties, dimensionless

$\beta \quad$ Local collection efficiency, dimensionless

$\beta_{0} \quad$ Collection efficiency at stagnation line, dimensionless

$\theta \quad$ Air energy transfer parameter, ${ }^{\circ} \mathrm{C}$

$\lambda$ Droplet range, $\mathrm{m}$

$\lambda_{\text {Stokes }}$ Droplet range if Stokes Law applies, $\mathrm{m}$

$\Lambda_{f} \quad$ Latent heat of freezing, cal $/ \mathrm{g}$

$\Lambda_{v} \quad$ Latent heat of condensation, cal $/ \mathrm{g}$

$\mu \quad$ Air viscosity, $\mathrm{g} / \mathrm{m} \mathrm{s}$

$\mu_{w} \quad$ Liquid water viscosity, $\mathrm{g} / \mathrm{m} \mathrm{s}$

$\rho \quad$ Air density, $\mathrm{g} / \mathrm{m}^{3}$

$\rho_{i} \quad$ Ice density, $\mathrm{g} / \mathrm{m}^{3}$

$\rho_{w} \quad$ Liquid water density, $\mathrm{g} / \mathrm{m}^{3}$

$\sigma \quad$ Surface tension of water over air, dyne $/ \mathrm{cm}$

$\tau \quad$ Accretion time, min

$\phi \quad$ Droplet energy transfer parameter, ${ }^{\circ} \mathrm{C}$

$\underline{\text { Subscripts }}$

$\begin{array}{ll}R & \text { Reference } \\ S & \text { Scale }\end{array}$




\section{$\underline{\text { Introduction }}$}

Although a number of similarity parameters have been identified as possibly being important in determining ice shape, there have been only a few studies that have attempted to evaluate how each parameter affects the ice shape or how closely scale and reference values of the similarity parameters must agree. This paper reviews both published and unpublished ice-shape data in an attempt to gain further insight.

By the 1970's it was well recognized that there were at least 6 basic similarity parameters that needed to be considered in performing scaling tests. They were the modified inertia parameter, $K_{0}$, defined by Langmuir and Blodgett ${ }^{1}$, the accumulation parameter, $A_{c}$, the freezing fraction, $n$, the water-energy transfer parameter, $\phi$, the air-energy transfer parameter, $\theta$ and the relative heat factor, $b$. The parameters $n, \phi$, and $\theta$ are from the analysis of Messinger, ${ }^{2}$ and $b$ was defined by Tribus. ${ }^{3}$ Different scaling methods match scale values of various parameters to their respective reference values to obtain a set of simultaneous equations that are solved for the required scale test conditions. Charpin and Fasso $^{4}$ were the first to incorporate most of these parameters into a scaling method for sea-level testing facilities. By the mid 1980's Ruff ${ }^{5}$ established that the most faithful scaling resulted when five of these parameters (ignoring $b$ ) were matched in a facility with control of test-section pressure. Soon after, Bartlett ${ }^{6,7,8}$ performed a series of analytical and experimental studies to try to determine how important these parameters were to the ice shape. Could any of them be ignored? How closely did each have to be matched to insure an acceptable scaled ice shape?

There are several important reasons to do studies of the kind Bartlett did. First, in planning scale tests, it is not always possible to achieve precisely the scaled conditions required to match all of the scaling parameters. Therefore, some flexibility in choosing test conditions is helpful. For example, if the test facility cannot produce the droplet size needed to exactly match modified inertia parameters, it is useful to know if other values inside the tunnel operating map might provide ice shapes with acceptable agreement. Second, the test conditions are only known within some uncertainty band; thus, it is important to know what levels of uncertainties are acceptable when doing scaled tests. Finally, identifying the similarity parameters with the greatest effect on ice shape can be helpful in understanding the physics of icing.

The questions that Bartlett began to consider have not yet been adequately answered. The present approach to scaling is still to match each parameter precisely and determine the scaled test conditions accordingly. There is now, however, additional data which will be reviewed in this paper to add further insight into the relevance and acceptable variation of several similarity parameters.

\section{$\underline{\text { Similarity Parameters }}$}

The similarity parameters used in icing scaling have been identified by examining the physics of icing. Similarity of each of several processes needs to be maintained between the scale and the reference situations.

The first of these processes is the flowfield. It can be simulated by matching scale and reference values of $R e$ and $M$, by using a model that is dimensionally similar to the full-scale (reference) article and by setting the scale angle of attack equal to the reference. For icing encounters, the speeds involved are typically low enough that compressibility is not an issue, and $M$ is neglected. Although $R e$ has usually been ignored as well, Bilanin ${ }^{9}$ advocated including it in icing scaling analyses, and some recent studies ${ }^{10}$ have used $R e=$ $V d \rho / \mu$ as an optional scaling parameter. Here $d$ is the diameter for cylindrical models or twice the leadingedge radius for airfoils. In this study, $d$ was also used as the geometric length scale for the parameters $K, A_{c}$, $h_{c}$, and $W e_{c}$. For the NACA 0012, a leading-edge radius of $.0158 c$ was used; for the business jet, $.013 c$, where $c$ is the model chord.

The next process to be represented is the droplet motion. Similarity of droplet trajectories can be obtained by matching the modified inertia parameter, $K_{0}$, of Langmuir and Blodgett: ${ }^{1}$

$$
K_{0}=\frac{1}{8}+\frac{\lambda}{\lambda_{\text {Stokes }}}\left(K-\frac{1}{8}\right)
$$

$\lambda / \lambda_{\text {Stokes }}$ is the droplet range parameter, defined as the ratio of actual droplet range to that if Stokes law for solid-sphere drag applied. The range parameter is a function only of the droplet Reynolds number, $R e_{\delta}$. Langmuir and Blodgett presented tabulations of this function. $K$ is the inertia parameter,

$$
K=\frac{\rho_{w} M V D^{2} V}{18 d \mu}
$$

The water-droplet collection efficiency at the stagnation line is directly dependent on the modified inertia 
parameter. Langmuir and Blodgett gave this relationship:

$$
\beta_{0}=\frac{1.40\left(K_{0}-1 / 8\right)^{0.84}}{1+1.40\left(K_{0}-1 / 8\right)^{0.84}}
$$

Eq. (3) was used to calculate all the $\beta_{0}$ 's for this report. Although this relationship gives only the value of collection efficiency at the stagnation line, if two similar airfoils have the same $K_{0}$, the collection efficiency will also match everywhere on the two airfoils.

The third consideration is total ice accretion. The quantity of ice is represented by the accumulation parameter, $A_{c}$ :

$$
A_{c}=\frac{L W C V \tau}{d \rho_{i}}
$$

A match of scale and reference $A_{c}$ insures that the same quantity of ice, relative to airfoil size, is accreted for both. This matching assumes that $\beta_{0}$ for scale and reference situations also matches.

Next, for glaze ice, similarity in energy balance is required. Messinger's ${ }^{2}$ surface energy balance can be written in the form,

$$
n=\frac{c_{p, w s}}{\Lambda_{f}}\left(\phi+\frac{\theta}{b}\right)
$$

where $n$ is the freezing fraction; $\phi$, the water energy transfer parameter; $\theta$, the air energy transfer parameter; and $b$, the relative heat factor, introduced by Tribus, et. al. ${ }^{3}$ These parameters are defined as

$$
\begin{aligned}
& \phi=t_{f}-t_{s t}-\frac{V^{2}}{2 c_{p, w s}} \\
& \theta=\left(t_{s}-t_{s t}-\frac{r V^{2}}{2 c_{p}}\right)+\frac{h_{G}}{h_{c}}\left(\frac{p_{w w}-p_{w}}{p}\right) \Lambda_{v} \\
& b=\frac{L W C V \beta_{0} c_{p, w s}}{h_{c}}
\end{aligned}
$$

The last processes to be considered occur on the surface of the model where water collects before freezing. For rime ice, water freezes on impact so that there is no liquid-water film; therefore, surface dynamics are only relevant to glaze-ice accretions. The physical processes on the liquid surface are not yet well understood, but similarity parameters related to surface effects can be identified that may be important. These include the capillary number, $N_{c a p}=\mu_{w} V / \sigma$, included by $\mathrm{Kind}^{11}$ in a recent study, as well as the Weber numbers, $W e=$ $V^{2} M V D \rho_{w} / \sigma$ and $W e_{c}=V^{2} d \rho / \sigma$. Kind suggested that a Weber number based on the water-film thickness might also be considered. In addition, the free-stream Reynolds number, $R e$, probably plays a role in waterfilm dynamics.

Finally, the non-dimensional water-film thickness itself may well be a similarity parameter of importance in describing water-film dynamics. Feo and Urdiales ${ }^{12}$ gave an experimental correlation for water-film height for heavy-rain conditions, and $\mathrm{Feo}^{13}$ also recently measured the film thickness for near-Appendix-C cloud conditions in a warm-air tunnel. No other experimental studies applicable to icing are known to have been published. A limited unpublished study by Anderson ${ }^{14}$ showed good icing scaling results when Feo's latest expression for film thickness normalized to the model size was matched between scale and reference conditions. While encouraging, these results are still preliminary and will not be included here.

In this paper, the sensitivity of ice shapes to variations in $K_{0}, A_{c}, n, R e, W e$ and $W e_{c}$ will be discussed. Other parameters will not be considered because there is insufficient data to evaluate their effect. $K_{0}$ and $n$ are determined at the stagnation line of the model only. It is assumed that values there will be proportional to values anywhere on the airfoil. The effects of static pressure, $p_{s t}$, on both the similarity parameters and ice shape will also be reviewed to help assess the importance of some of the parameters for icing. The evaluations will be made for glaze ice. The ice shapes used for illustration were obtained in the NASA Glenn Icing Research Tunnel by various researchers.

\section{Effects of Parameters on Ice Shape}

Modified Inertia Parameter, $K_{0}$

An indication of the possible effect of $K_{0}$ on ice shapes can be deduced from its effect on collection efficiency. Figure 1 shows the relationship between $\beta_{0}$ and $K_{0}$ given by eq. (3). Note that for $K_{0}$ greater than $1, \beta_{0}$ increases less than $10 \%$ for a $K_{0}$ increase of $25 \%$. Between 2 and $3, K_{0}$ has to vary by more than $50 \%$ for $\beta_{0}$ to change $10 \%$. When $K_{0}$ has reached a value of 3 , the collection efficiency is already nearly $80 \%$, and $K_{0}$ has to triple to a value of 9 for $\beta_{0}$ to increase from 80 to 


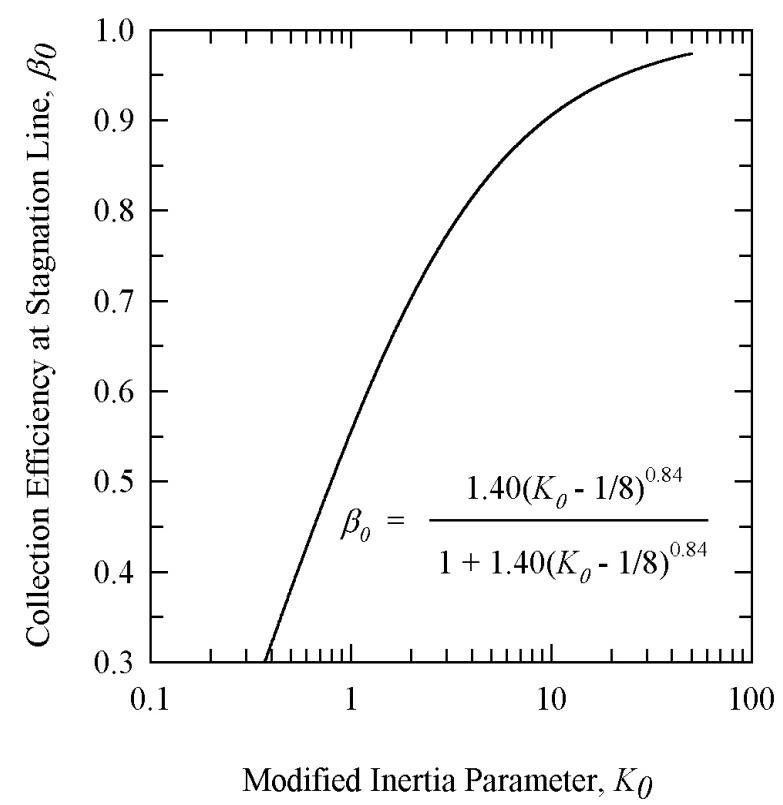

Figure 1. Relationship between $K_{0}$ and the Langmuir and Blodgett ${ }^{1} \beta_{0}$.

$90 \%$. Bartlett ${ }^{8}$ assumed that a $\pm 10 \%$ variation in ice shape could typically be expected when tests were repeated. Therefore, a $10 \%$ variation in $\beta_{0}$ is probably within run-to-run variations, and it is apparent that over much of the range of $K_{0}$ shown in figure 1, a perfect match of this similarity parameter is unnecessary to insure scaling results within repeatability expectations.

$K_{0}$ and collection efficiency are dependent on velocity, droplet size and model size. Of most interest to practical scaling applications is how much flexibility in the choice of scale $M V D$ results from relaxing the requirement that $K_{0, S}=K_{0, R}$. While it is always preferable to test with scale droplet sizes as close to the exact solution as possible, in some situations, the scaling equations may yield scale $M V D$ 's that are outside the tunnel cloud capability. Estimates of permissible variations in droplet size can be made from plots of $\beta_{0}$ as a function of $M V D$. Figure 2 shows two sets of such plots. Each curve represents either a reference or scale condition for an NACA 0012 airfoil of a specific size. A reference velocity of $67 \mathrm{~m} / \mathrm{s}$ was chosen, and the scale conditions were determined using the Ruff method, described in reference 10. The scale velocity was the average of the velocities that resulted from applying constant-We and constant-Re constraints.

Figure 2(a) shows curves for 53- and 27-cm-chord airfoils. For a reference $M V D$ of $30 \mu \mathrm{m}$, a scale $M V D$ of $15.6 \mu \mathrm{m}$ was found by matching scale and reference $K_{0}$. The reference and scale $M V D$ 's are shown as open and solid circles, respectively. The stagnation-line collection efficiency for these drop sizes was .80 . For the example shown, it can be seen that a scale droplet size as large as $25 \mu \mathrm{m}$ would only increase the scale stagnation-point collection efficiency by $10 \%$.

Larger models allow less flexibility in choosing the scale droplet size. For example, figure 2(b) gives the

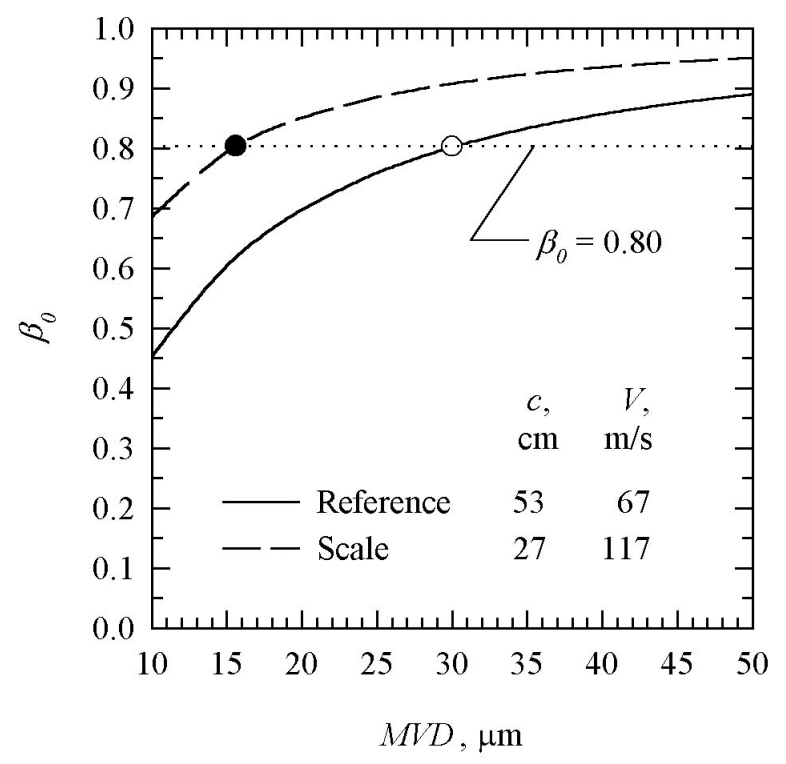

(a) Scaling from 53.3- to 26.7-cm Chord.

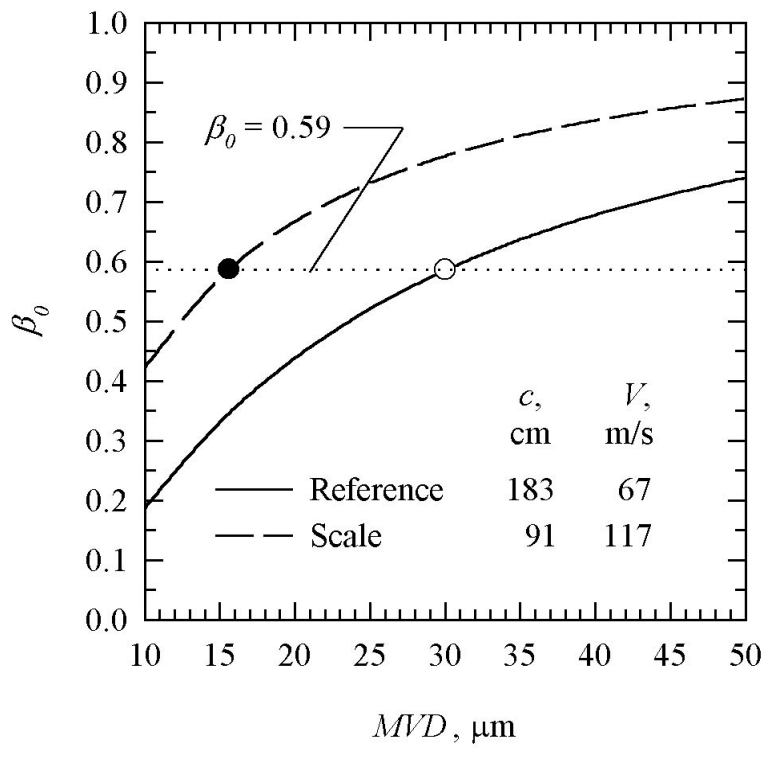

(b) Scaling from 183- to 91-cm Chord.

Figure 2. Examples of Collection Efficiency for $1 / 2$ Size Scaling. NACA 0012 Airfoils at $0^{\circ}$ AOA. 
same scaling situation as figure 2(a), but for reference and scale model chords of 183 and $91 \mathrm{~cm}$. Although the scale $M V D$ found from $K_{0, S}=K_{0, R}$ is still $15.6 \mu \mathrm{m}$, the collection efficiency for both models is now only .59. Restricting the scale $\beta_{0}$ to be no more than $10 \%$ higher than the reference requires that the scale drop size be no larger than $19 \mu \mathrm{m}$, instead of the $25 \mu \mathrm{m}$ found for the conditions of figure 2(a).

If alternate drop sizes are contemplated, the full collection-efficiency curve over the region of expected ice accretion for the model at the off-scale conditions should be compared with that for the reference case to insure that differences are small. It is also important to remember that measured drop sizes cannot be precisely defined. In the IRT, for example, the drop size uncertainty has been estimated to be $\pm 11 \%{ }^{15}$ Thus, the difference between the alternative drop size and the exact-solution value must be greater than $11 \%$ to be significant.

This flexibility in choosing scale drop size can be confirmed with experimental results. Ice shapes obtained in the IRT by various researchers are compared in figures 3 and 4 . The ice-shape data were reported by Wright. ${ }^{16}$ All were obtained on $53-\mathrm{cm}-$ chord NACA 0012 airfoils at $4^{\circ}$ angle of attack. Combinations of test conditions were selected for each of the comparisons such that constant $A_{c}, n, b, \phi$, and $\theta$ were maintained, but $K_{0}$ 's were different. Coincidentally, $R e$ and $W e_{c}$ also matched. The test

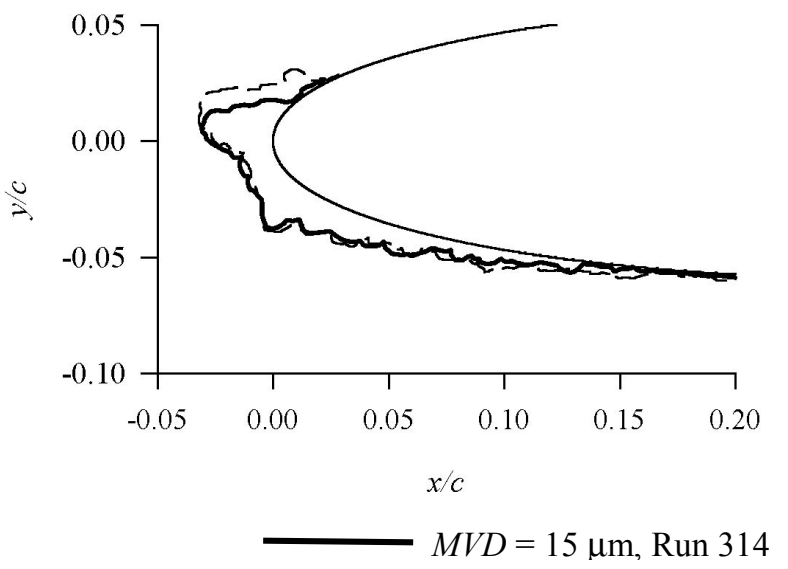

(a) Ice Shapes

\begin{tabular}{|c|c|c|c|c|c|c|c|c|c|c|c|c|c|c|c|c|}
\hline Run & $\begin{array}{l}t_{s t}, \\
{ }^{\circ} \mathrm{C}\end{array}$ & $\begin{array}{c}t_{t o t}, \\
{ }^{\circ} \mathrm{C}\end{array}$ & $\begin{array}{c}V \\
\mathrm{~m} / \mathrm{s}\end{array}$ & $\begin{array}{c}M V D \\
\mu \mathrm{m}\end{array}$ & $\begin{array}{c}L W C, \\
\mathrm{~g} / \mathrm{m}^{3}\end{array}$ & $\begin{array}{c}\tau \\
\sec \end{array}$ & $K_{0}$ & $\beta_{0}$ & $A_{c}$ & $n$ & $b$ & $\begin{array}{l}\phi, \\
{ }^{\circ} \mathrm{C}\end{array}$ & $\begin{array}{l}\theta, \\
{ }^{\circ} \mathrm{C}\end{array}$ & $\begin{array}{l}R e \\
10^{4}\end{array}$ & $\begin{array}{l}W e \\
10^{3}\end{array}$ & $\begin{array}{c}W e_{c} \\
10^{3}\end{array}$ \\
\hline 314 & -10.8 & -5.6 & 102.8 & 15.0 & 0.60 & 384 & 1.63 & 0.66 & 1.53 & 0.53 & 0.34 & 9.6 & 11.2 & 13.0 & 2.44 & 3.40 \\
\hline 303 & -10.8 & -5.6 & 102.8 & 20.0 & 0.55 & 420 & 2.56 & 0.75 & 1.54 & 0.52 & 0.36 & 9.6 & 11.2 & 13.0 & 3.25 & 3.40 \\
\hline
\end{tabular}

conditions for each test and the corresponding similarity parameters are shown below the data plots.

In figure 3(a), ice shapes produced with drop sizes of 15 and $40 \mu \mathrm{m}$ are compared. The corresponding $K_{0}$ 's were 1.63 and 2.56 . The $\beta_{0}$ were calculated to be .66 and .75 , respectively. In addition to the $K_{0}$ differences, the $W e$ for the two cases were 2.44 and $3.25 \times 10^{3}$. The ice shapes differ mainly in the size and extent of the upper horn, with the higher $K_{0}$ leading to a slightly larger horn. The differences were little more than typical run-to-run variations.

Figure 3(b) compares the clean-airfoil collectionefficiency curves for the conditions of the two icing tests of 3(a). The $\beta$ 's were calculated using LEWICE 2.0. ${ }^{17}$ The largest differences between $\beta$ curves were seen on the lower surface. In spite of these differences, the lower-surface ice shown in figure 3(a) agreed well for the two tests, presumably because the absolute value of $\beta$ was low where the curves deviated the most. The $\beta$ curves showed only minor differences between the accretion limits for the two tests.

Figure 4(a) compares shapes formed with $M V D$ 's of 25 and $40 \mu \mathrm{m}$. These drop sizes corresponded with $K_{0}=$ 3.62 and 7.54. The $\beta_{0}$ were .80 and .88 , respectively. Again, all other similarity parameters were matched except $W e$. The ice shapes were in close agreement including both the upper horn and a large feather structure just aft of the upper horn. It can be seen from

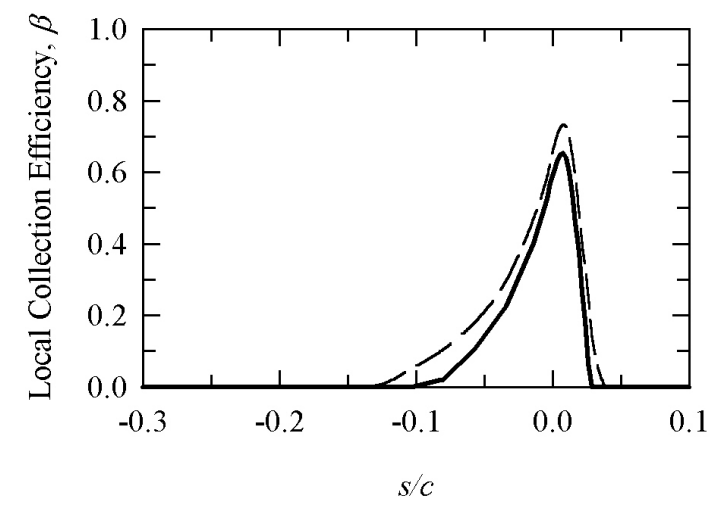

- - $M V D=20 \mu \mathrm{m}$, Run 303

(b) Collection Efficiency

Figure 3. Effect of $K_{0}$ on Ice Shape. 53.3-cm-Chord NACA 0012 Airfoil at $4^{\circ} \mathrm{AOA}$. Ice-Shape Data from Addy, April 1997, reported in CD's accompanying Wright. ${ }^{16}$ Collection Efficiencies Calculated Using LEWICE. ${ }^{17}$ 


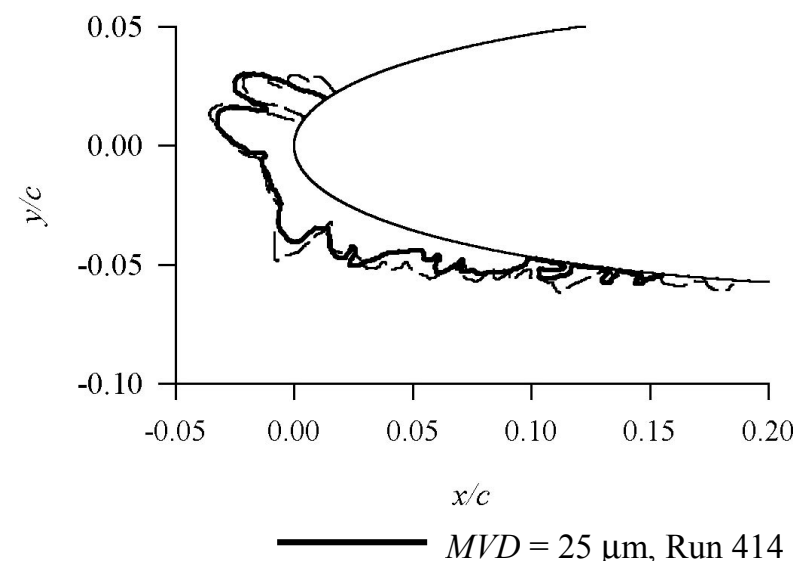

(a) Ice Shapes

\begin{tabular}{|c|c|c|c|c|c|c|c|c|c|c|c|c|c|c|c|}
\hline $\begin{array}{l}t_{s t}, \\
{ }^{\circ} \mathrm{C}\end{array}$ & $\begin{array}{c}t_{t o t}, \\
{ }^{\circ} \mathrm{C}\end{array}$ & $\begin{array}{l}V, \\
\mathrm{~m} / \mathrm{s}\end{array}$ & $\begin{array}{c}M V D \\
\mu \mathrm{m}\end{array}$ & $\begin{array}{l}L W C, \\
\mathrm{~g} / \mathrm{m}^{3}\end{array}$ & $\begin{array}{c}\tau, \\
\sec \end{array}$ & $K_{0}$ & $\beta_{0}$ & $A_{c}$ & $n$ & $b$ & $\begin{array}{l}\phi \\
{ }^{\circ} \mathrm{C}\end{array}$ & $\begin{array}{l}\theta, \\
{ }^{\circ} \mathrm{C}\end{array}$ & $\begin{array}{l}R e \\
10^{4}\end{array}$ & $\begin{array}{l}W e \\
10^{3}\end{array}$ & $\begin{array}{c}W e_{c}, \\
10^{3}\end{array}$ \\
\hline-10.8 & -5.6 & 102.8 & 25.0 & 0.55 & 420 & 3.62 & 0.80 & 1.54 & 0.49 & 0.38 & 9.6 & 11.2 & 13.0 & 4.06 & 3.40 \\
\hline-11.2 & -5.9 & 102.8 & 40.0 & 0.50 & 462 & 7.54 & 0.88 & 1.54 & 0.51 & 0.38 & 9.9 & 11.7 & 13.0 & 6.50 & .41 \\
\hline
\end{tabular}

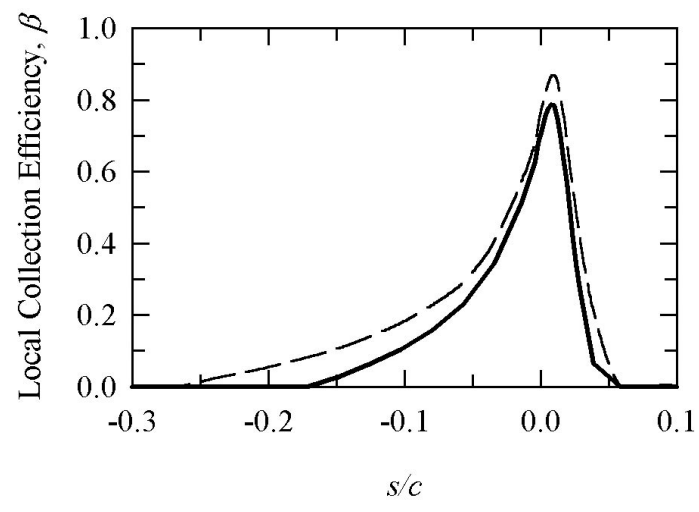

- - - $M V D=40 \mu \mathrm{m}$, Run 413

(b) Collection Efficiency

Figure 4. Effect of $K_{0}$ on Ice Shape. 53.3-cm-Chord NACA 0012 Airfoil at $4^{\circ}$ AOA. Ice-Shape Data from Bidwell and Van Zante, January 1998, reported in CD's accompanying Wright. ${ }^{16}$ Collection Efficiencies Calculated Using LEWICE. ${ }^{17}$

figure 4(b) that the lower-surface collection-efficiency for the two runs did not match even as well as those for the cases given in figure 3 , but again these differences did not appear to have much effect on the lower-surface ice actually accreted.

These experimental comparisons show that scale and reference values of $\beta_{0}$ can differ by $10-11 \%$ without a significant effect on ice shape. As a guideline, when the scale droplet size determined by setting $K_{0, S}=K_{0, R}$ is outside the capability of a test facility, alternate values of $M V D$ can be substituted, providing $\beta_{0}$ for the new $M V D$ is within $10 \%$ of the reference value and $\beta$ curves for the scale and reference airfoils do not deviate significantly.

\section{Accumulation Parameter, $A_{c}$}

The accumulation parameter directly determines the quantity of ice produced. In scaling calculations, the matching of scale and reference $A_{c}$ (see eq. (4)) allows the determination of the scale spray time. In principle, time can be set easily in test facilities, so that there is no need for the scale value of this parameter to deviate from the reference. However, for short spray times, spray-system stabilization may be a significant portion of the total spray for some facilities. The IRT now has a rapid-start spray system that avoids this problem. The uncertainty in $A_{c}$ has been estimated to be about $\pm 12 \%{ }^{15}$ in the IRT, due to uncertainties in the test conditions other than time. Thus, the uncertainty in the total quantity of ice accreted will be no better than $\pm 12 \%$, and to avoid misleading results, shielding of the model during spray stabilization or corrections to the accretion time may need to be considered for some facilities.

If the scale stagnation collection efficiency is different from the reference, instead of matching $A_{c}$, the product $A_{c} \beta_{0}$ should be matched as closely as possible between reference and scale.

\section{Freezing Fraction, $n$}

The freezing fraction is primarily a function of temperature, airspeed and $L W C$, but it is the scale $L W C$ that is usually found by equating scale and reference freezing fraction. For most situations, there is no practical advantage in allowing the scale $n$ to deviate from the reference, for if the scale value of $L W C$ found initially from solving the scaling equations is not suitable, an alternate value can be selected by applying the Olsen method. ${ }^{18}$ This method requires simply that the scale temperature be adjusted for the new $L W C$ so that $n_{S}=n_{R}$ is maintained.. However, due to testcondition uncertainties, $n$ is only known to within about $\pm 10 \%{ }^{15}$, so it is useful to know what kinds of variations in ice shape can be expected.

The importance of the freezing fraction in determining glaze ice shapes has long been recognized. In 1986, 
Olsen, et al. ${ }^{19}$ showed the effect of systematic changes in temperature on ice shape with all other test conditions fixed. When freezing fractions are calculated from Olsen's reported test conditions, it can be shown that ice shapes changed little when $n$ varied by less than $10 \%$. In reference 18 , tests were reported in which $L W C$ was varied and ice shapes were recorded on cylinders mounted vertically in the IRT. When the temperature was adjusted to maintain constant $n$, ice shapes showed only minor random variations. When temperature was fixed so that $n$ varied with $L W C$, the ice shapes changed more significantly.

Some of the results from reference 18 will be repeated here along with other unpublished data from that study. Figure 5 gives ice shapes resulting when the freezing fraction was varied with all test conditions except $L W C$ fixed. Note from the table accompanying figure 5 that all the similarity parameters except $n$ and $b$ were also constant. For the test conditions in this example, an increase in $L W C$ from .8 to $.9 \mathrm{~g} / \mathrm{m}^{3}$ reduced the freezing

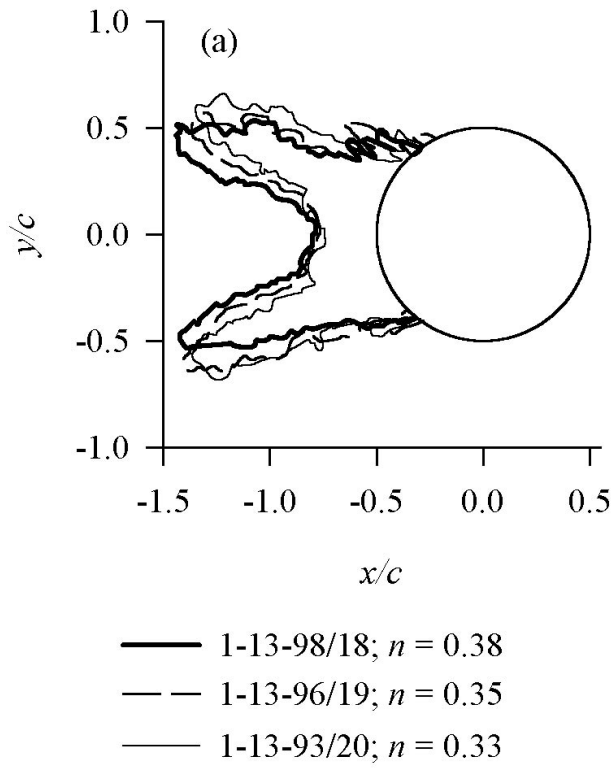

(a) Liquid-Water Contents of $0.8,0.9$ and $1.0 \mathrm{~g} / \mathrm{m}^{3}$. fraction from .38 to .35 . Figure 5(a) shows how the resulting glaze-ice horns spread apart slightly, shifting aft on the model as $n$ decreased. The change in horn angle for this modest change in $n$ was no greater than that typically seen when tests are repeated at the same test conditions. A further increase in $L W C$ from .9 to $1.0 \mathrm{~g} / \mathrm{m}^{3}$ reduced $n$ from .35 to .33 and resulted in a slight additional spreading of the horns. The overall change in $n$ was about $13 \%$, which produced a noticeable, but probably not significant, effect on ice shape.

Figure 5(b) gives the results of larger changes in $n$. $L W C$ 's were $.8,1.1$ and $1.3 \mathrm{~g} / \mathrm{m}^{3}$ with corresponding freezing fractions of $.38, .31$ and .29 . Consistent with the trend seen in figure 5(a), the horns spread out as the freezing fraction decreased. The reduction of $n$ from .38 to .29 , representing a change of $24 \%$, produced significant changes in horn position for these fairly large accretions. For small accumulation parameters (short accretion times), however, differences over the

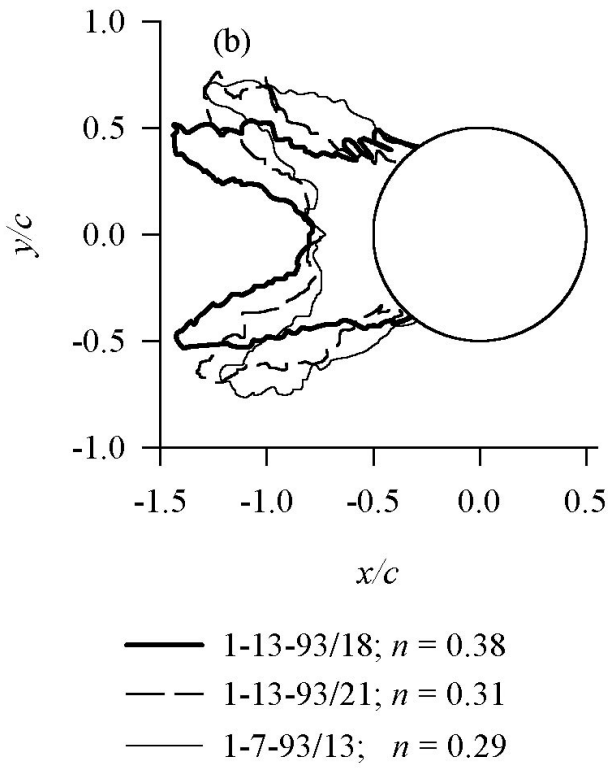

(b) Liquid-Water Contents of $0.8,1.1$ and $1.3 \mathrm{~g} / \mathrm{m}^{3}$.

$\begin{array}{ccccccccccccccccc}\text { Date/Run } & \begin{array}{c}t_{s t}, \\ { }^{\circ} \mathrm{C}\end{array} & \begin{array}{c}t_{\text {tot }}, \\ { }^{\circ} \mathrm{C}\end{array} & \begin{array}{c}V, \\ \mathrm{~m} / \mathrm{s}\end{array} & \begin{array}{c}M V D, \\ \mu \mathrm{m}\end{array} & \begin{array}{c}L W C, \\ \mathrm{~g} / \mathrm{m}^{3}\end{array} & \begin{array}{c}\tau, \\ \min \end{array} & K_{0} & \beta_{0} & A_{c} & n & b & \begin{array}{c}\phi, \\ { }^{\circ} \mathrm{C}\end{array} & \begin{array}{c}\theta, \\ { }^{\circ} \mathrm{C}\end{array} & \begin{array}{c}R e, \\ 10^{4}\end{array} & \begin{array}{c}W e, \\ 10^{3}\end{array} & \begin{array}{c}W e_{\mathrm{c}}, \\ 10^{3}\end{array} \\ 1-13-93 / 18 & -12.2 & -7.8 & 94.0 & 30.0 & 0.80 & 12.7 & 1.57 & 0.66 & 1.23 & 0.38 & 0.75 & 11.2 & 14.0 & 36.5 & 4.07 & 8.68 \\ 1-13-93 / 19 & -12.2 & -7.8 & 94.0 & 30.0 & 0.90 & 11.3 & 1.57 & 0.66 & 1.23 & 0.35 & 0.84 & 11.2 & 14.0 & 36.5 & 4.07 & 8.68 \\ 1-13-93 / 20 & -12.2 & -7.8 & 94.0 & 30.0 & 1.0 & 10.1 & 1.57 & 0.66 & 1.22 & 0.33 & 0.94 & 11.2 & 14.0 & 36.5 & 4.07 & 8.68 \\ 1-13-93 / 21 & -12.2 & -7.8 & 94.0 & 30.0 & 1.1 & 9.2 & 1.57 & 0.66 & 1.22 & 0.31 & 1.03 & 11.2 & 14.0 & 36.5 & 4.07 & 8.68 \\ 1-7-93 / 13 & -12.2 & -7.8 & 94.0 & 30.0 & 1.3 & 7.8 & 1.57 & 0.66 & 1.23 & 0.29 & 1.22 & 11.2 & 14.0 & 36.5 & 4.07 & 8.68\end{array}$

Figure 5. Effect of Freezing Fraction on Ice Shape. 5.1-cm-Diameter Vertical Cylinder Tested in the NASA Glenn IRT. Published ${ }^{18}$ and Unpublished Ice-Shape Data from Tests by Anderson. 
range of freezing fraction tested in figure 5(b) would probably not be substantial.

The results in figures 5(a) and (b) demonstrate how sensitive ice-shape is to freezing fraction. For scaled tests for which the objective is to simulate a reference ice shape, the $\pm 10 \%$ uncertainty in $n$ leaves no flexibility to permit $n_{S}$ to deviate from $n_{R}$.

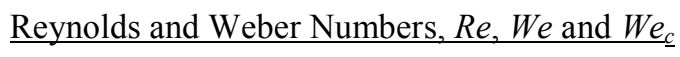

Any of these parameters can be matched to their reference values to determine the scale velocity. While they have not usually been included in scaling studies, Anderson and Ruff ${ }^{10}$ showed that scaling methods incorporating $R e$ and $W e$ were more successful than methods that didn't. Reference 15 found the best scaling when $V_{S}$ was determined by a compromise between constant $R e$ and constant We. This compromise put both parameters in the range of approximately 60 to $160 \%$ of the reference values.

Figures 3 and 4 above compared ice shapes from pairs of tests for which $R e$ and $W e_{c}$ matched. We for run 303 in figure 3 was $133 \%$ of that for run 314 . For the tests of figure $4 \mathrm{We}$ for run 413 was $160 \%$ of that for run 414. In both cases, the ice shapes matched well in spite of these $W e$ differences. These results and those of reference 15 suggest that, if $W e$ matters at all, an approximate match between reference and scale values of $W e$ is sufficient for good matches of ice shape.

One of the properties included in the definition of $W e$ is the surface tension. To demonstrate the importance of surface tension, and possibly $W e$, on ice shape, Bilanin
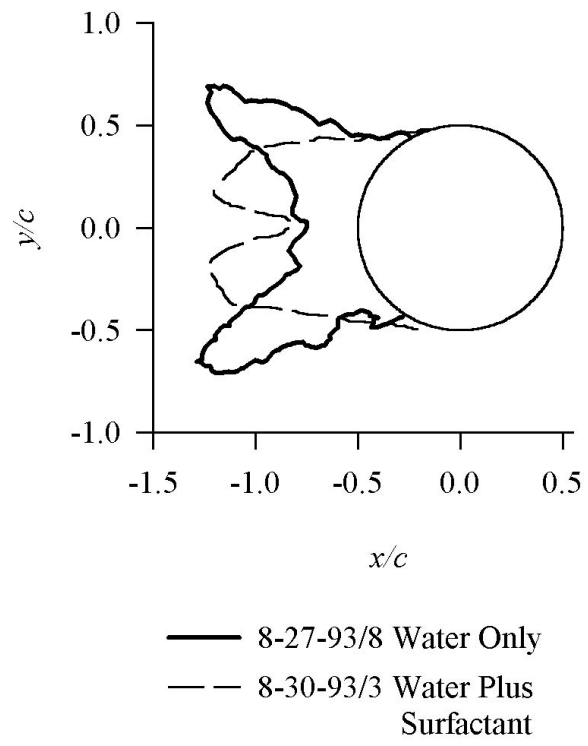

(a) Same Model Size and Test Conditions.
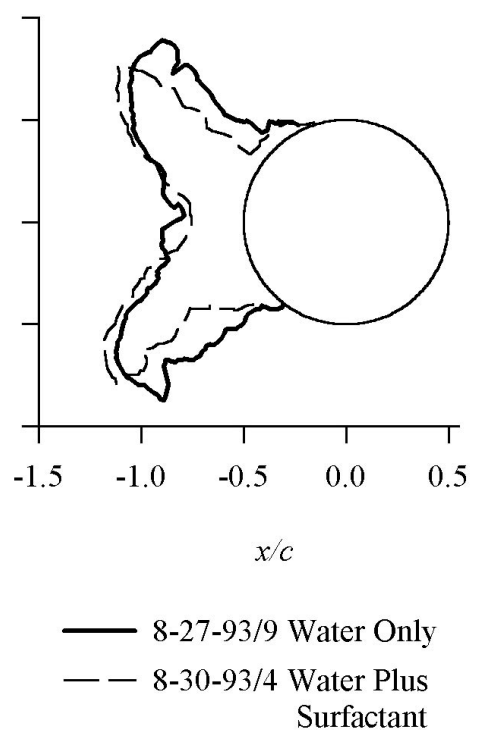

(b) Same Model Size; Test Conditions Adjusted to Approximate $W e$.
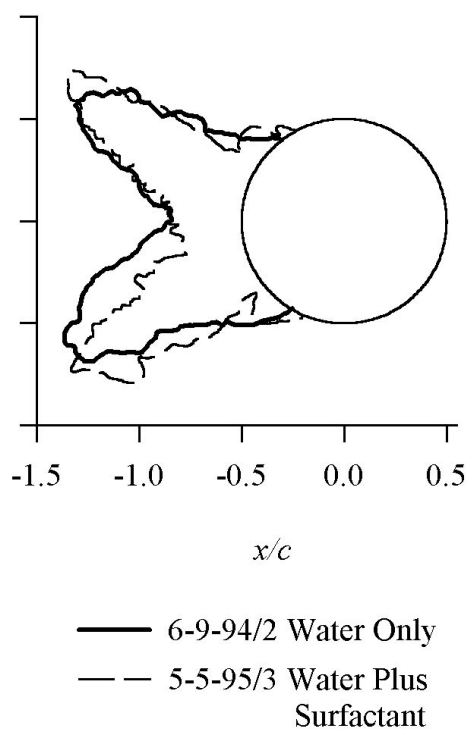

(c) Model Size Varied and Test Conditions Adjusted to Match We and $R e$.

\begin{tabular}{|c|c|c|c|c|c|c|c|c|c|c|c|c|c|c|c|c|}
\hline Date/Run & $\begin{array}{c}d \\
\mathrm{~cm}\end{array}$ & $\begin{array}{l}t_{t o t}, \\
{ }^{\circ} \mathrm{C}\end{array}$ & $\begin{array}{c}V, \\
\mathrm{~m} / \mathrm{s}\end{array}$ & $\begin{array}{c}M V D \\
\mu \mathrm{m}\end{array}$ & $\begin{array}{c}L W C, \\
\mathrm{~g} / \mathrm{m}^{3}\end{array}$ & $\underset{\min }{\tau}$ & $K_{0}$ & $\beta_{0}$ & $A_{c}$ & $n$ & $b$ & $\begin{array}{l}\phi, \\
{ }^{\circ} \mathrm{C}\end{array}$ & $\begin{array}{l}\theta, \\
{ }^{\circ} \mathrm{C}\end{array}$ & $\begin{array}{l}R e \\
10^{4}\end{array}$ & $\begin{array}{l}W e \\
10^{3}\end{array}$ & $\begin{array}{c}W e_{c}, \\
10^{3}\end{array}$ \\
\hline & 5. & -7.8 & 1.0 & 30.0 & 1.10 & 9.2 & 57 & 66 & .22 & & & 11.2 & 14.0 & 36.4 & 4.08 & 87 \\
\hline & & .6 & & 0.0 & & & & 6 & & & & & & 36.4 & 75 & 187 \\
\hline-21 & & 9.6 & 0.9 & 4.1 & 1.39 & 2 & .56 & .66 & $2 \angle$ & & & & & 26.7 & .35 & .5 \\
\hline $8-30-93 / 4$ & 3.1 & -6.9 & 46.8 & 40.0 & 1.17 & 16.0 & 1.60 & 0.66 & 1.13 & 0 & 6 & 7.7 & $J$ & 18.5 & 2.91 & 48 \\
\hline $9-$ & 0.1 & 10.1 & 5 & 9 & .00 & 14.3 & 1.25 & 0.0 & 1.2 & 0 & U. & 11.8 & 10 & 26.9 & 2.05 &.+ \\
\hline $5-5-95 / 3$ & .6 & -8.3 & 40.9 & 8.0 & 0.99 & 33.9 & 0.94 & 0.54 & 1.18 & 0.39 & 0.60 & 8.9 & 13.4 & 24.5 & 2.1 & 55 \\
\hline
\end{tabular}

Figure 6. Effect of Surfactant on Ice Shape. Vertical Cylinders Tested in the NASA Glenn IRT. Published ${ }^{20}$ and Unpublished Ice-Shape Data from Tests by Bilanin and Anderson. 
and Anderson ${ }^{20}$ performed a series of tests in the IRT in August 1993 with surfactant added to the spray water. Figure 6 gives three sets of ice-shape comparisons resulting from these tests.

Figure 6(a) compares ice shapes obtained from two tests with the same model size and test conditions, except that for the first test the spray was with water only while the second used a water-surfactant mixture. The two tests produced matching values of all similarity parameters except for the two Weber numbers. We and $W e_{c}$ for the surfactant-addition test were more than double those for the water-only test. The dramatic difference between the two ice shapes shows that simply matching $K_{0}, A_{c}, n, b, \phi, \theta$ and $R e$ is not sufficient, and either $W e$ or $W e_{c}$ also has a significant effect on ice shape.

In figure 6(b) another pair of ice shapes are compared with the same model size. Again, one shape was obtained with water only and one with surfactant added to the spray. For these two tests, however, test conditions differed in such a way that $W e$ and $W e_{c}$ for the surfactant-addition test were no more than $124 \%$ of

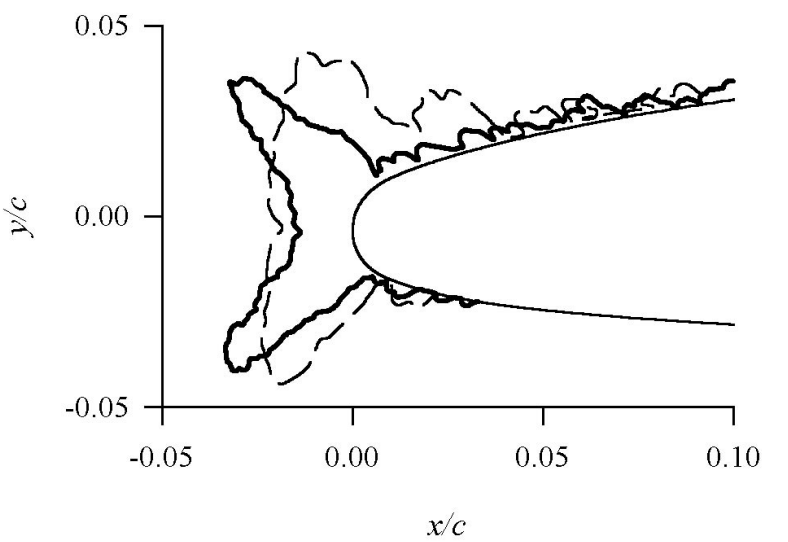

$$
\begin{aligned}
& -3-13-98 \operatorname{Run} 736.31 ; c=91.4 \mathrm{~cm} \\
& - \text { - 3-6-98 Run } 718.31 ; c=45.7 \mathrm{~cm}
\end{aligned}
$$

(a) Constant-Velocity Scaling; $R e_{S} / R e_{R}=0.49$;

\begin{tabular}{|c|c|c|c|c|c|c|c|c|c|c|c|c|c|c|c|c|c|}
\hline Run & $\begin{array}{l}c, \\
\mathrm{~cm}\end{array}$ & $\begin{array}{l}t_{s t}, \\
{ }^{\circ} \mathrm{C}\end{array}$ & $\begin{array}{l}t_{t o t}, \\
{ }^{\circ} \mathrm{C}\end{array}$ & $\begin{array}{c}V, \\
\mathrm{~m} / \mathrm{s}\end{array}$ & $\begin{array}{c}M V D \\
\mu \mathrm{m}\end{array}$ & $\begin{array}{l}L W C, \\
\mathrm{~g} / \mathrm{m}^{3}\end{array}$ & $\begin{array}{c}\tau, \\
\sec \end{array}$ & $K_{a}$ & $\beta_{1}$ & $A_{\text {A }}$ & $r$ & $b$ & $\begin{array}{l}\phi, \\
{ }^{\circ} \mathrm{C}\end{array}$ & $\begin{array}{l}\theta, \\
{ }^{\circ} \mathrm{C}\end{array}$ & $\begin{array}{l}R e \\
10^{4}\end{array}$ & $\begin{array}{l}W e \\
10^{3}\end{array}$ & $\begin{array}{l}W e_{c_{2}} \\
10^{3}\end{array}$ \\
\hline & 1.4 & 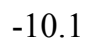 & -6.0 & 91 & 45.0 & & 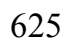 & 5.97 & 86 & 57 & & & & 11.4 & 6.4 & 5.70 & 3.78 \\
\hline & .7 & .9 & -6 & 8 & 9.0 & & 241 & 5.86 & 6 & 3 & & & 0 & .4 & 8.0 & 19 & 80 \\
\hline & & & -0.0 & & & & & & & & & & & & 6.4 & & \\
\hline & 7 & 1.2 & .6 & 05 & 7.0 & .35 & 200 & 5.87 & 0.86 & 2.61 & 0.29 & 0 . & 9.9 & 1.4 & 9.4 & 4.6 & 25 \\
\hline
\end{tabular}
$W e_{S} / W e_{R}=0.61$.

Figure 7. Scaling to $1 / 2$ Size. Business Jet Airfoil at $0^{\circ}$ AOA Tested in the NASA Glenn IRT. Ice-Shape Data from Tests by Chen. ${ }^{21}$ surfactant-addition test was about $70 \%$ of that for the water-only test, and all other similarity parameters either matched or nearly matched. While the two ice shapes of figure 6(b) were not in perfect agreement, they were similar in most characteristics.

Finally, in figure 6(c), both test conditions and size were altered when surfactant was added. Both $W e$ and $R e$ for the surfactant-addition test were within $10 \%$ of the water-only test, while $W e_{c}$ for the two tests were within $21 \%$. Most of the other similarity parameters except $K_{0}, \phi$ and $\theta$ agreed within $10 \%$ for the two tests, as well. Ice shapes were again in close agreement.

The comparison of the results of figure 6(a) with either (b) or (c) provides a powerful argument for including $W e$ or $W e_{c}$ as a scaling parameter. It is clear that while scale $R e, W e$ and $W e_{c}$ may not have to match their respective reference values closely, differences in the Weber numbers of a factor of 2 are not acceptable.

These conclusions can be further confirmed by looking at the results of a series of 1998 scaling tests performed by $\mathrm{Chen}^{21}$ without surfactant addition. Figure 7 gives
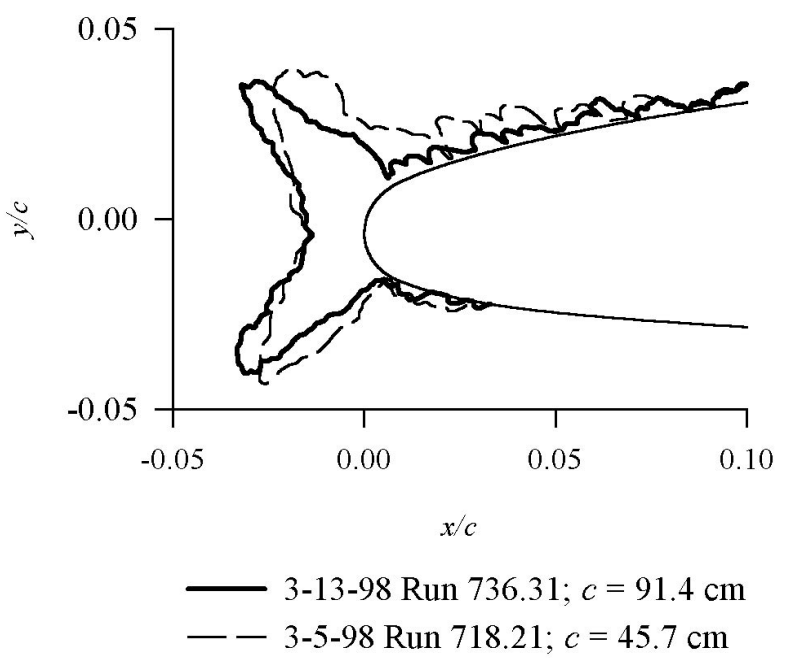

(b) Scaling with $V_{S} / V_{R}=1.15 ; R e_{S} / R e_{R}=0.58$;

$W e_{S} / W e_{R}=0.82$. 
Chen's results of scaling from a reference model of 91-cm chord to a scale with 46-cm chord. In figure 7(a), ice shapes are compared for the situation in which the scale velocity (run 718.31) nearly matched the reference (run 736.31). Other conditions were such that the similarity parameters $K_{0}, A_{c}, n, \phi$, and $\theta$ also matched. However, the scale $R e$ was about $50 \%$ of the reference value, the scale $W e$ was about $60 \%$ and the scale $W e_{c}$ was about $48 \%$. While the quantity of ice obtained in the scale test was about right, the shape did not agree with the reference.

For the shapes shown in figure 7(b), the reference test was again 736.31, as in figure 7(a). Scale conditions now gave $R e, W e$ and $W e_{c}$ that were 58, 82 and $67 \%$, respectively, of their reference values while $K_{0}, A_{c}, n, b$, and $\theta$ matched. While the scale shape was not a perfect representation of the reference, its simulation was greatly improved over that of figure 7(a).

For the test conditions reported in figure $7(\mathrm{c})$, the scale Reynolds number was now $67 \%$ of the reference value, and $W e$ and $W e_{c}$ were 104 and $88 \%$ of the reference

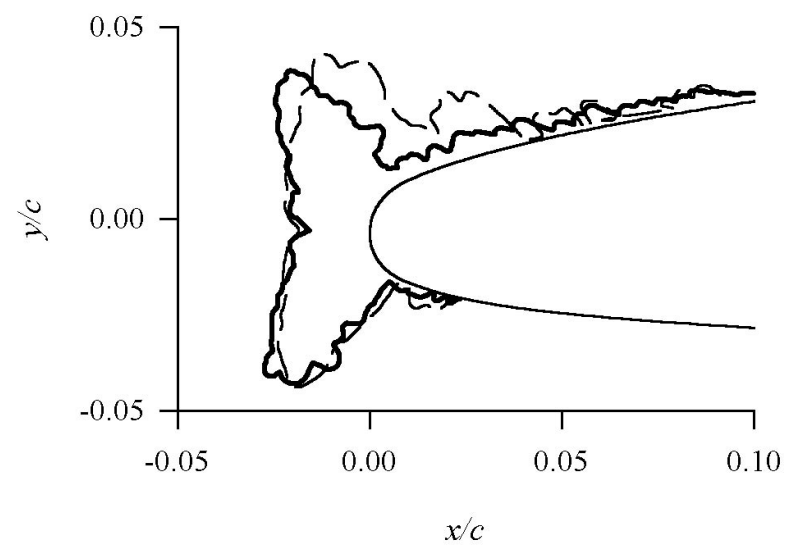

$$
\begin{aligned}
& -3-11-98 \text { Run } 736.11 ; c=91.4 \mathrm{~cm} \\
& --3-6-98 \text { Run } 718.31 ; c=45.7 \mathrm{~cm}
\end{aligned}
$$

(c) Constant-We Scaling; $V_{S} / V_{R}=1.33 ; R e_{S} / R e_{R}=$ $0.66 ; W e_{S} / W e_{R}=1.03$. values, respectively. Simulation of the reference shape was quite good except for the upper horn position. Scale conditions for these tests again resulted in a match of reference values of $K_{0}, A_{c}, n, b$, and $\theta$.

Finally, for figure 7(d), the scale $R e, W e$ and $W e_{c}$ were 73,124 and $109 \%$ of the reference values, respectively, and the scale parameters $K_{0}, A_{c}, n$, and $\theta$ matched the respective reference values. The scale ice shape for this test was an excellent simulation of the reference shape. Without changing surface tension, it is not possible to match both $R e$ and $W e$ simultaneously. However, the scale values of $R e$ and $W e$ for the tests of figure 7(d) represent a compromise between perfect matching of either parameter with their reference values.

Chen's data, those of figures 3 and 6 and the results in reference 15 consistently indicated that the best scaling can be obtained when both the scale $R e$ and scale $W e$ are between approximately 60 and $160 \%$ of their respective reference values.

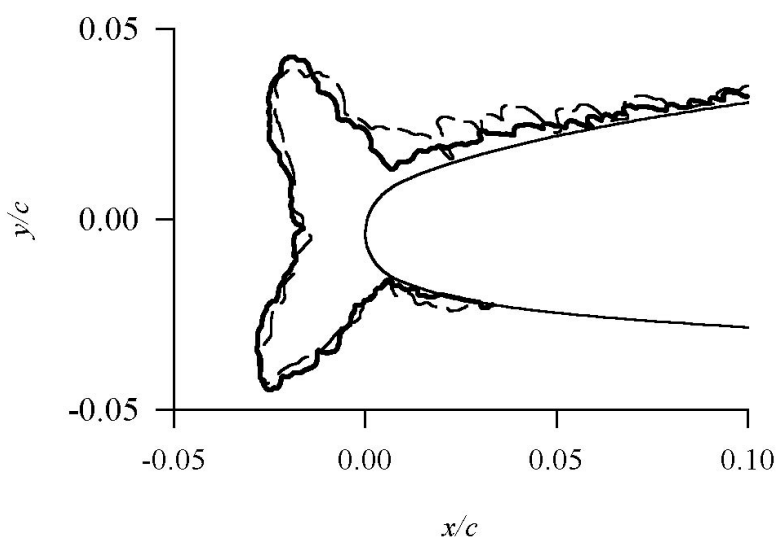

3-12-98 Run 736.21; $c=91.4 \mathrm{~cm}$

3-5-98 Run $718.21 ; c=45.7 \mathrm{~cm}$

(d) Scaling with Compromise Between Constant-Re and Constant-We; $V_{S} / V_{R}=1.48 ; \operatorname{Re}_{S} / \operatorname{Re}_{R}=0.73$;

\begin{tabular}{|c|c|c|c|c|c|c|c|c|c|c|c|c|c|c|c|c|c|}
\hline $\mathrm{R}$ & $\begin{array}{l}c, \\
\mathrm{~cm}\end{array}$ & $\begin{array}{l}t_{s t} \\
{ }^{\circ} \mathrm{C}\end{array}$ & $\begin{array}{c}t_{t o t} \\
{ }^{\circ} \mathrm{C}\end{array}$ & $\begin{array}{c}V, \\
\mathrm{~m} / \mathrm{s}\end{array}$ & $\begin{array}{c}M V D \\
\mu \mathrm{m}\end{array}$ & $\begin{array}{l}L W C, \\
\mathrm{~g} / \mathrm{m}^{3}\end{array}$ & $\begin{array}{l}\tau, \\
\text { sec }\end{array}$ & $K_{0}$ & $\beta_{0}$ & $A_{c}$ & & $b$ & $\begin{array}{l}\phi, \\
{ }^{\circ} \mathrm{C}\end{array}$ & $\begin{array}{l}\theta, \\
{ }^{\circ} \mathrm{C}\end{array}$ & $\begin{array}{l}R e \\
10^{4}\end{array}$ & $\begin{array}{l}W e \\
10^{3}\end{array}$ & $\begin{array}{l}W e_{c}, \\
10^{3}\end{array}$ \\
\hline & 1.4 & .7 & -6.6 & 66 & 50.0 & 1.07 & 30 & 1 & 86 & .69 & 30 & & 8.2 & 1.4 & 12.0 & 3.35 & 2.04 \\
\hline & 5.7 & -9.9 & -6.1 & 88 & 29.0 & 1 & 241 & 5.86 & 0.86 & 3 & 0.30 & 077 & 9.0 & 4 & .0 & 3.49 & 188 \\
\hline & & & -6.3 & 11 & U. & .01 & & & 0.0 & & & & & & 2.9 & .8 & 2. \\
\hline & 5.7 & 1.2 & -5.6 & 106 & 7.0 & .35 & 200 & 5.87 & 0.86 & 2.61 & 0.29 & 0.85 & 9.9 & 11.4 & 9.4 & 4.65 & .5 \\
\hline
\end{tabular}
$W e_{S} / W e_{R}=1.24$.

Figure 7. (concluded). 


\section{Effect of Pressure on Similarity Parameters}

A knowledge of the effect of pressure on both ice shapes and similarity parameters can help to determine which similarity parameters have the most influence on ice shape. For example, if a change in pressure produces a large effect on a particular similarity parameter, but little effect on ice shape, it can be concluded that ice shapes are insensitive to that parameter.

Studies to evaluate the effect of pressure on ice shapes have been reported by Bartlett ${ }^{6,7}$ over the range of 3.0 to $9.8 \times 10^{4} \mathrm{Nt} / \mathrm{m}^{2}$ and by Oleskiw, et al. ${ }^{22}$ for pressures of 4.6 to $10.1 \times 10^{4} \mathrm{Nt} / \mathrm{m}^{2}$. Within the typical repeatability of test facilities there was no evidence from either study that pressure change affected the ice shape.

Table I shows how pressure affects calculated values of each of the scaling parameters. An NACA 0012 with a chord of $53.3 \mathrm{~cm}$ was used in the computations. The greatest effect of pressure is on $K_{0}, \theta, b, R e$ and $W e_{c}$, while $\beta_{0}, A_{c}, \phi, n$, and $W e$ are not affected, or the effect is slight. Even for a chord of $183 \mathrm{~cm}$, the effect of pressure on $\beta_{0}$, over the range of pressure shown and for the velocity given, would be less than $10 \%$. For higher velocities, the variation of $\beta_{0}$ with pressure will be even less. Thus, the lack of an effect of pressure on ice shape is consistent with the small effect of pressure on modified inertia parameter and stagnation collection efficiency. Although both $\theta$ and $b$ change with pressure, the ratio $\theta / b$ is nearly constant; thus, no conclusions can be reached about the importance of either of these parameters on ice shape.

$R e$ is nearly directly proportional to pressure due to the effect of pressure on air density. This strong pressure

Table I. Effect of Pressure on Similarity Parameters 53.3-cm-Chord NACA 0012 Airfoil

$\begin{array}{cccccc}t_{s t},-6.7^{\circ} \mathrm{C} ; t_{\text {tot }},-4.4^{\circ} \mathrm{C} ; V, 67 \mathrm{~m} / \mathrm{s} ; M V D, 30 \mu \mathrm{m} ; \\ p_{s t}, 10^{4} \mathrm{Nt} / \mathrm{m}^{2} & 9.72 & 8.43 & 6.97 & 5.72 & 4.65 \\ K_{0} & 3.70 & 3.90 & 4.18 & 4.48 & 4.80 \\ \beta_{0}, \% & 80.3 & 81.0 & 81.9 & 82.8 & 83.6 \\ A_{c} & 1.91 & 1.91 & 1.91 & 1.91 & 1.91 \\ n & 0.27 & 0.27 & 0.27 & 0.27 & 0.27 \\ b & 0.57 & 0.61 & 0.68 & 0.76 & 0.85 \\ \phi,{ }^{\circ} \mathrm{C} & 6.1 & 6.1 & 6.1 & 6.1 & 6.1 \\ \theta,{ }^{\circ} \mathrm{C} & 8.5 & 9.1 & 10.1 & 11.4 & 13.0 \\ R e, 10^{4} & 8.54 & 7.41 & 6.13 & 5.03 & 4.09 \\ W e, 10^{3} & 2.07 & 2.07 & 2.07 & 2.07 & 2.07 \\ W e_{c}, 10^{3} & 1.47 & 1.28 & 1.06 & 0.87 & 0.71\end{array}$

effect suggests that ice shapes are fairly insensitive to $R e$, and changes by a factor of 2 or more in this parameter appear to be tolerable. Further evaluation of $R e$ effects are needed.

Earlier discussion showed that when the Weber number changed by a factor of 2 , as $W e_{c}$ does for the range of pressures given in Table I, the shape of the ice changed dramatically. Thus, for ice shapes to be independent of pressure, $W e_{c}$ cannot be the correct form of Weber number. Either $W e$, which is unaffected by pressure change, or any Weber number using water properties, appears to be the proper expression of this similarity parameter.

\section{$\underline{\text { Summary }}$}

This study of how ice shapes are affected by variations in the scaling similarity parameters has resulted in the following tentative guidelines on acceptable deviations of scale parameters from the corresponding reference values:

1. The scale $K_{0}$ does not need to match the reference value closely, but the permissible deviation depends on the reference value. It is recommended that as a guideline, the scale $\beta_{0}$ should be within $10 \%$ of the reference value, where $\beta_{0}$ is related to $K_{0}$ according to the expression given in eq (3). Furthermore, if a scale $M V D$ is selected that does not satisfy $K_{0, S}=K_{0, R}$, the scale and reference collection efficiencies along both the reference and scale airfoil surfaces should be computed and compared to insure that differences are minor.

2. Uncertainties in $A_{c}$ should not be permitted to exceed about $\pm 10 \%$ to insure a reasonable match of ice shapes. This similarity parameter depends on the spray time. When spray times are short, they may need to be corrected to account for spray-bar system stabilization periods. When the scale $\beta_{0}$ does not match the reference value, the product $A_{c} \beta_{0}$ should be matched.

The following comments pertain only to glaze conditions. For rime conditions, none of the parameters $n, R e$ and $W e$ or $W e_{c}$ have an influence on ice shape.

3. The scale $n$ should be held to within $10 \%$ of the reference value. This tolerance is the same as estimated uncertainties in the freezing fraction. Thus, the goal should be to try to match this parameter to its reference value.

4. Acceptable scale $R e$ and $W e$ fall in the range of 60 to $160 \%$ of the respective reference values. Evaluation of pressure effects on ice shape 
suggested that even greater tolerances on Re may be possible, and $W e_{c}$ is apparently not the right form of Weber number to be used as a similarity parameter.

Insufficient information was available to determine how the remaining parameters, $\phi, \theta$ and $b$, affect ice shape or how closely scale values of these parameters might need to be matched to their reference values.

\section{$\underline{\text { References }}$}

1 Langmuir, Irving and Blodgett, Katharine B.: "A Mathematical Investigation of Water Droplet Trajectories," Army Air Forces Technical Report No. 5418, February 1946.

2 Messinger, B.L., "Equilibrium Temperature of an Unheated Icing Surface as a Function of Airspeed," J. Aeron. Sci. vol. 20 no. 1, January 1953, pp 29-42.

${ }^{3}$ Tribus, Myron, Young, G.B.W. and Boelter, L.M.K., "Analysis of Heat Transfer Over a Small Cylinder in Icing Conditions on Mount Washington," Trans. ASME vol. 70, November 1948, pp 971-976.

${ }^{4}$ Charpin, Francois and Fasso, Guy, "Essais de givrage dans la grande soufflerie de Modane sur maquettes a echelle grandeur et echelle reduite," L'Aeronautique et l'Astronautique, no. 38, 1972, pp 23-31. English translation published as "Icing Testing in the Large Modane Wind-Tunnel on Full-Scale and Reduced Scale Models," NASA TM-75373, March 1979.

5 Ruff, G.A., "Analysis and Verification of the Icing Scaling Equations," AEDC-TR-85-30, Vol 1 (Rev), March 1986.

6 Bartlett, C.Scott, "An Analytical Study of Icing Similitude for Aircraft Engine Testing," DOT/FAA/CT86/35 and AEDC-TR-86-26, October 1986.

7 Bartlett, C. Scott, "Icing Scaling Considerations for Aircraft Engine Testing," AIAA-88-0202, 26 ${ }^{\text {th }}$ Aerospace Sciences Meeting, January 1988.

${ }^{8}$ Bartlett, C. Scott, "An Empirical Look at Tolerances in Setting Icing Test Conditions with Particular Application to Icing Similitude," DOT/FAA/CT-87/31 and AEDC-TR-87-23, August 1988.

9 Bilanin, A.J., "Proposed Modifications to the Ice Accretion/Icing Scaling Theory," AIAA Paper AIAA-88-0203, January 1988.

${ }^{10}$ Anderson, David N. and Ruff, Gary A., "Evaluation of Methods to Select Scale Velocities in Icing Scaling Tests," AIAA-99-0244, January 1999.
${ }^{11}$ Kind, R.J., Dillon, T., Gaydos, J.A. and Oleskiw, M., "Evidence for the Importance of Scaling Viscous Effects in the Water Film in Glaze Icing Tests," AIAA98-0196, January 1998.

${ }^{12}$ Feo, A. and Urdiales, M., "Stagnation Point Probe in a Water Spray Immersed in an Airstream," $\phi A E / T N O / 0452 / 003 / I N T A / 95$, Instituto Nacional de Técnica Aeroespacial, February 1995.

${ }^{13}$ Feo, A., "Icing Scaling with Surface Film Thickness Similarity for High LWC Conditions," AE/PRO/4420/184/INTA/00, Instituto Nacional de Técnica Aeroespacial, October 2000.

${ }^{14}$ Anderson, David N., unpublished NASA Glenn Icing Research Tunnel study, November 2000.

15 Anderson, David N., "Effect of Velocity in Icing Scaling Tests," AIAA-2000-0236, January 2000.

${ }^{16}$ Wright, William B., "Validation Report for LEWICE 2.0," NASA CR 208690, January 1999. An accompanying 2-CD set contains digitized ice-shape data.

${ }^{17}$ Wright, William B., "User Manual for the NASA Glenn Ice Accretion Code LEWICE Version 2.0," NASA CR-1999-209409, September 1999.

${ }^{18}$ Anderson, David N., "Methods for Scaling Icing Test Conditions," AIAA-95-0540 and NASA TM-106827, January 1995

19 Olsen, William, Newton, James and Shaw, Robert, "Ice Shapes and the Resulting Drag Increase for a NACA 0012 Airfoil,” NASA TM-83556, January 1986

20 Bilanin, Alan J. and Anderson, David N., "Ice Accretion with Varying Surface Tension," AIAA-950538 and NASA TM-106826, January 1995.

21 Chen, Shu-cheng, unpublished NASA Glenn Icing Research Tunnel study, March 1998.

22 Oleskiw, Myron M., De Gregorio, Fabrizio and Esposito, Biagio, "The Effect of Altitude on Icing Tunnel Airfoil Icing Simulation," Proceedings of the FAA International Conference on Aircraft Inflight Icing, DOT/FAA/AR-96/81,II, August 1996, pp. 511520 . 
Public reporting burden for this collection of information is estimated to average 1 hour per response, including the time for reviewing instructions, searching existing data sources, gathering and maintaining the data needed, and completing and reviewing the collection of information. Send comments regarding this burden estimate or any other aspect of this collection of information, including suggestions for reducing this burden, to Washington Headquarters Services, Directorate for Information Operations and Reports, 1215 Jefferson Davis Highway, Suite 1204, Arlington, VA 22202-4302, and to the Office of Management and Budget, Paperwork Reduction Project (0704-0188), Washington, DC 20503.

\begin{tabular}{|l|l|l|}
\hline 1. AGENCY USE ONLY (Leave blank) & $\begin{array}{c}\text { 2. REPORT DATE } \\
\text { June } 2003\end{array}$ & $\begin{array}{c}\text { 3. REPORT TYPE AND DATES COVERED } \\
\text { Final Contractor Report }\end{array}$ \\
\hline
\end{tabular}

\section{TITLE AND SUBTITLE}

Acceptable Tolerances for Matching Icing Similarity Parameters

in Scaling Applications

\section{AUTHOR(S)}

David N. Anderson

\section{PERFORMING ORGANIZATION NAME(S) AND ADDRESS(ES)}

Ohio Aerospace Institute

22800 Cedar Point Road

Brook Park, Ohio 44142

WU-708-20-13-00

NCC3-884

\section{SPONSORING/MONITORING AGENCY NAME(S) AND ADDRESS(ES)}

National Aeronautics and Space Administration

Washington, DC 20546-0001

\section{PERFORMING ORGANIZATION} REPORT NUMBER

E-13514

\section{SUPPLEMENTARY NOTES}

Prepared for the 39th Aerospace Sciences Meeting and Exhibit sponsored by the American Institute of Aeronautics and Astronautics, Reno, Nevada, January 8-11, 2001. Project Manager, Thomas H. Bond, Turbomachinery and Propulsion Systems Division, NASA Glenn Research Center, organization code 5840, 216-433-3900.

12a. DISTRIBUTION/AVAILABILITY STATEMENT

Unclassified - Unlimited

Subject Category: 02

\section{2b. DISTRIBUTION CODE}

Available electronically at http://gltrs.grc.nasa.gov

This publication is available from the NASA Center for AeroSpace Information, 301-621-0390.

\section{ABSTRACT (Maximum 200 words)}

This paper reviews past work and presents new data to evaluate how changes in similarity parameters affect ice shapes and how closely scale values of the parameters should match reference values. Experimental ice shapes presented are from tests by various researchers in the NASA Glenn Icing Research Tunnel. The parameters reviewed are the modified inertia parameter (which determines the stagnation collection efficiency), accumulation parameter, freezing fraction, Reynolds number, and Weber number. It was demonstrated that a good match of scale and reference ice shapes could sometimes be achieved even when values of the modified inertia parameter did not match precisely. Consequently, there can be some flexibility in setting scale droplet size, which is the test condition determined from the modified inertia parameter. A recommended guideline is that the modified inertia parameter be chosen so that the scale stagnation collection efficiency is within 10 percent of the reference value. The scale accumulation parameter and freezing fraction should also be within 10 percent of their reference values. The Weber number based on droplet size and water properties appears to be a more important scaling parameter than one based on model size and air properties. Scale values of both the Reynolds and Weber numbers need to be in the range of 60 to 160 percent of the corresponding reference values. The effects of variations in other similarity parameters have yet to be established.

14. SUBJECT TERMS

Aircraft icing; Scaling; Aircraft safety
15. NUMBER OF PAGES

18

16. PRICE CODE

\begin{tabular}{|c|c|c|}
\hline $\begin{array}{c}\text { 17. SECURITY CLASSIFICATION } \\
\text { OF REPORT } \\
\text { Unclassified }\end{array}$ & $\begin{array}{c}\text { 18. SECURITY CLASSIFICATION } \\
\text { OF THIS PAGE } \\
\text { Unclassified }\end{array}$ & $\begin{array}{c}\text { 19. SECURITY CLASSIFICATION } \\
\text { OF ABSTRACT } \\
\text { Unclassified }\end{array}$ \\
\hline
\end{tabular}

NSN 7540-01-280-5500

Standard Form 298 (Rev. 2-89) 